"This is an Author's Accepted Manuscript of an article published as Individualized Housing Careers in Early Adulthood: Conditions and Constraints

in a Familistic Society Sociological Research Online, Volume 15, Issue 1, 2010 [copyright Sociological Research Online]"

DOI http://dx.doi.org/10.5153/sro.2079 


\title{
Individualized Housing Careers in Early Adulthood: Conditions and Constraints in a Familistic Society
}

\author{
by Magda Nico \\ CIES, ISCTE-IUL, Centre for Research and Studies in Sociology \\ ISCTE-IUL - Lisbon University Institute
}

Sociological Research Online, Volume 15, Issue 1,

< http://unw. socresonline.org.uk/15/1/6. htm/>

doi:10.5153/sro. 2079

Received: 23 Jul 2009 Accepted: 6 Jan 2010 Published: 28 Feb 2010

\begin{abstract}
This article discusses the unsteady and uncertain conditions in which a potentially individualized life course co-exists with and survives in a so-called institutionalized, standardized, familistic and sub-protective society. For the purpose, non-family living in early adulthood in a southern European country (Portugal) is taken as the example. On one hand, data from the 2006 European Social Survey ( 23 countries, $N=43000$ ) is used to contextualize the Portuguese transition to adulthood and the preconceptions about the so-called familistic societies in general. On the other hand, data on events and values from a small sample of young adults living alone in Portugal (aged 24-30, $\mathrm{N}=120$, approximately $1 \%$ of the universe considered), along with official statistics on a housing programme for these young adults (Rental Incentive for Young People), allows us to analytically deconstruct preconceptions about the relation between intergenerational support and welfare policies in familistic societies. This data demonstrates most of all how a mismatch between the still-prevailing institutionalization of life courses in some societies and the reflexivity characterizing contemporary biographies produces critical points in young people's lives. It also demonstrates the adaptability of family cultures to these 'choice biographies' in comparison to the lack of adaptability of some youth policies, in particular those involving housing. These processes of mismatching and misunderstanding reflect and promote the inadequacy and inefficiency of communication between youth research and policy-making.
\end{abstract}

\section{Keywords: Life Course, Individualization, Transition(S) to Adulthood, Non-Family Living}

\section{Introduction}

1.1 How do young people adapt their 'choice biographies' (Bois-Reymond, 1998) in familistic societies, that is, contexts strongly orienting young adults towards a 'normal biography' and an institutionalized life course? How are intergenerational support networks affected by this mismatch? What is the relationship between the public and private mechanisms for institutionalizing a person's life course: complementarity or alternation?

1.2 This set of questions is raised in relation to the individualization thesis, closely associated with the debate on the dualistic view of the standardized life cycle/de-standardized life course (for this critique see Elchardus and Smits, 2006). Starting from this point, this article demonstrates the usefulness of studying the simultaneity of an institutionalized and familistic society with minority individualized trajectories (with counter-cultural and age norms), for two processes. First, for the deconstruction of the preconceptions about intergenerational support in familistic societies in general (versus, in particular, the Scandinavian model) and, second, for the questioning of the bipolarized perspective of risk and choice biographies, on the one hand, and a normal or 'tripartite' biography (Kohli, 1985), on the other. Transitions to adulthood are often made through involuntary conversions of choice into normal biographies, which the specific trajectories presented in the last section of this article precisely demonstrates. This allows us to contribute evidence to the comprehension of individualisation as a 'structured individualisation' (Evans and Heinz, 1994; Nagel and Wallace, 1997).

1.3 While Portugal is taken here as an example of a conservative welfare state with a sub-protective system of transitions to adulthood (Walther, 2006) and a high regard for and percentage of home-ownership (orienting young adults towards a normal biography), leaving home to live alone is a paradigmatic and exceptional trajectory in the Portuguese transition to adulthood. That is to say, it is a choice biography apparently disregarding cultural and age norms relating to the close relationship between conjugality and transition to adulthood in general (on this matter, see Nico, 2008a).

1.4 The article is divided into three parts. One briefly presents and discusses the reconciliation or mismatch between individualization processes and institutionalized societies, along with the bipolar way of understanding these processes. The aim is to argue that this dichotomy, even if only analytical, may distort 
the interpretation of the trajectories to adulthood throughout Europe. Using data from the 2006 European Social Survey on age norms and practices in transitional events to adulthood, the Portuguese specificity, a familistic and sub-protective society, is put into perspective. This corresponds to the second part. In the third part, data collected on young adults with the specific trajectory mentioned and the benefit of a public incentive towards the rental option allowed us to understand how they and their families adapt to different expectations, possibilities and choices in the transition to adulthood and 'housing careers' (Ineichen, 1981). This also allows us to explain the rise of the 'independent living' strategies of young adults in Portugal, and their subsequent fall.

1.5 The final remarks close the argument on the poor contribution of the welfare state 'labels and clusters' to the comprehension of the conversion of choice into normal biographies, and the adaptability of families' structures to both these biographies, in particular the process of shifting between them. In the same sense that Goodwin and O'Connor (2005) argue against the insufficient attention given to the individual level complexity in school to work transitions in the 1960s, this article aims to argue against the understatement on the level of complexity of the supposed normal biographies, namely concerning housing careers, constructed in familistic societies. That is to say that the appearance of 'normality' must not discourage the analysis of the complexity of the housing careers, taking the individualized ones as the best data to attenuate the distinction between 'choice' (non-linear) and 'normal' (linear) biographies. The final remarks also address the importance of efficient communication between research and policy-making.

\section{Individualized lives in institutionalized societies}

2.1 Many authors have joined the debate on the institutionalization versus individualization of a person's life course, arguing that the life course perspective has substituted that of the life cycle, which would apply more to non-modern contexts than modern ones (Giddens, 2001: 13). Elder argued that the life cycle perspective defined individual trajectories as a 'sequence of social roles that bear upon stages of parenthood, from the birth of children to their departure from the household and their eventual transition to the role of parent, setting in motion another life cycle' (Elder, 1998: 5). Although still a possibility, these normal trajectories are not the most paradigmatic in our contemporary society.

2.2 With regard to the individualization thesis, the scientific discussions on the life course perspective are central to the development of research that mobilizes the concepts of youth and adulthood, and is concerned with the trajectories between them. Moreover, according to Billari, 'the transition to adulthood can be viewed as a process with social and demographic passages from the educational system to the labour market and from the parental household to the individual's own household. The period around the transition to adulthood is demographically 'dense', that is, it encompasses a high density of demographic events (Rindfuss, 1991). (...) Clearly, such an orientation calls explicitly for the adoption of the life course perspective' (Billari, 2001: 119).

2.3 The two complementary features of the life course perspective will be briefly presented: (a) the destandardization, individualization and fragmentation of the life course (Bauman, 1991; Giddens, 2001; Beck, 1992; Settersten and Mayer, 1997; Arnett, 2000; Pais, 1993, 2001; Schwartz et al, 2005; Biggart and Walther, 2006; Vinken, 2007; Horowitz and Bromnick, 2007, among others); and (b) the institutionalization of the life course (Elder, 1975; Kohli, 1985, 2007; Mayer and Schoepflin, 1989; Billari, 2001, 2005, among others).

2.4 On the one hand, (a) the aspect of de-standardization, individualization and fragmentation of the life course 'focuses on the perceptions of individuals about the timing of life and (...) tries to understand how individuals perceive their options and how they plan their own future life course. Thus, its focus is on a cultural analysis of life courses, studying the life course 'as experienced". (Billari, 2005: 5). As far as the transitions to adulthood are specifically concerned, the yo-yo metaphor of Pais (2001) particularly illustrates the substitution of the life cycle perspective by that of the life course, namely in regarding its feature of destandardization and reversibility. In that sense it is argued that 'the linear model of juvenile transitions, where the conquest of adulthood was the accumulation of a series of sequential and ritualized stages (school, work, conjugality, parenthood), has been substituted by a fragmented one, characterized by the paradigmatic 'yo-yo transitions'. The sequential transitions multiply and become reversible, fragmented and concomitant. The multiplicity of transitions to adulthood creates a multiplicity of conceptions, attributed or claimed, about what it is to be an adult' (Pappámikail, 2004: 92-93). This feature of the life course is closely related to choice and risk biographies.

2.5 This brings us to the concept of contestable adulthood, suggested by Horowitz and Bromnick (2007). These authors argue that adulthood is an 'essentially contested concept', as Gallie (1962) understood and analysed it. Thus, with respect to adulthood, '(i) the concept concerns a valued achievement - it is appraisive; (ii) it is comprised of a collection of features or elements - it is internally complex; (iii) it is variously describable, in that there are many ways the concept can be defined, each giving primacy to different elements; (iv) changing circumstances elevate changing definitions of the concept to cultural ascendancy (in a way that cannot be predicted in advance) - its depiction is open; and, finally, (v) users of the concept show awareness that their formulations must be contested against those of others, who employ a competing ordering of criteria - it is used both aggressively and defensively.' (Horowitz and Bromnick, 2007: 211). Therefore, 'not only is the category 'adulthood' an essentially contestable concept but also any individual's membership of the category 'adult' is only contestable during a certain period of the life course. Before and after this time, it would be ridiculous to claim (before) or deny (after) membership of the 
2.6 The negotiation of the adult status occurs between different pacing of transitional events and different conceptions (within and between generations) of what it is to be an adult. Transitions, though reversible, represent the objective experiences of advances in the professional, familial, and residential spheres. It is in the context of such objective experiences and social conditions that young adults identify themselves and others with one of the categories - youngsters or adults - or both. The analytical distinction between transitions to adulthood and conceptions of adulthood is, according to Westerberg, a distinction between 'levels of transition' (Westberg 2004:37), and can be understood with others dichotomies such as independence and autonomy (according to Molgat (2007: 502-506), independence refers to financial aspects and autonomy has a more relational character), role transitions and status transitions (Westberg, 2004: 36-37), and transitional events and individual qualities (Molgat, 2007: 497).

2.7 On the other hand, (b) the institutionalization of the life course calls attention to the fact that, although the life course has become more de-standardized, individualized and fragmented, it is still under the strong influence of the welfare state, its restraints and possibilities, and its structures and institutions. This is especially important in a national analysis, where a mere cultural analysis of the life course is not sufficient and may even obscure the results. Thus, as stated by Billari, 'an institutionalisation perspective focuses on the actual occurrence and sequencing of the life course trajectories and tries to understand to what extent these trajectories are 'organized' by the State and by institutional arrangements in general. It also pays attention to actual changes in laws and policies such as age proscriptions and prescriptions (e.g. mandatory retirement, employment of youth).' (Billari, 2005: 5).

2.8 The objective experiences considered in the literature and statistical data as important markers of adulthood are usually 'being financially independent, having completed school, having a full time job, having the capacity to support a family, having left the parental home, getting married and having children' (Billari, 2005; see also Molgat, 2007: 498). Galland $(1984,1991)$ argues that the three most important transitional aspects are residential (the move from the parental home to a home of one's own), professional (the end of schooling and admission to the work market) and relational (the change from being single to living as a couple and family) (in Molgat, 2007: 495; see also Zittoun, 2002: 193, Oinonen, 2004: 286 and lacovou, 2001:1). This selection of transitional events is identical to that suggested by Pais, who argues that, as young adults begin to take responsibilities of an 'occupational (stable and paid job), conjugal or familial (expenses with children, for instance) or residential type (expenses with habitation and supporting the maintenance of the house)', they acquire adult status (1990: 141).

2.9 Thus, the most relevant and frequent institutional structures in this sort of research are the employment and housing markets ${ }^{[1]}$ (Billari, 2005), though the family is always embedded with these two. The emphasis given to these three structures may vary depending on the different national or thematic contexts, but it is generally agreed that the most relevant institutions, according to youth studies and studies of their transitions to adulthood, are, indeed, the family, the labour market, and the housing market. These used to be synchronized in the triangulation of life presented by Kohli (1985).

2.10 To identify - with the contribution of the Esping-Andersen's typology (1990) - (i) the heterogeneity of the relationship between agency and structure in different contexts of transition to adulthood and (ii) the way the subjective perspectives of young adults reflect these structures (i.e. identify national specificities in autobiographical discourses), Walther suggests a model of 'transition regimes' (Walther, 2006: 125-126). This typology assumes that 'national structures and institutions differ in the way in which they standardize life-courses and this leads to different concepts (and life-reality) for young adults. For example, in countries with poorly developed welfare states (e.g. Italy, Portugal, Spain), young adulthood emerges as a consequence of the lack of standardized institutions, the implementation of which would re-establish 'normal' transitions.' (EGRIS, 2001: 105).

2.11 For a brief glance at the Portuguese case, one could add that Portugal shares the 'sub-protective' transition regime with countries such as Spain and Italy (EGRIS, 2001: 105). According to Walther, this transition regime 'applies primarily to the Southern European countries, such as Italy, Spain and Portugal. Clustered among the 'conservative' welfare states by Esping-Andersen, the low percentage of standard work arrangements and the high rate of unprotected living conditions has created a 'dualistic' welfare regime in which the family and informal work play a significant role' (Walther, 2006: 129). In these countries, yo-yo transitions do not develop against dominant assumptions of the youth but rather emerge in a social vacuum. One might state that the transition system does not provide choice, flexibility, or security; they depend on the extent of family support'. (Walther, 2006: 129). Mills and Blossfeld have a similar argument, stating that southern European countries are 'family-oriented' (Mills and Blossfeld, 2005: 13-14).

2.12 The importance of the role of the family in Portugal has already been shown in qualitative national research. In this direction, Pappámikail mentions that 'as the state emerges as an insignificant social agent in the representation of the interviewees (young adults and their parents), it's the family, a dense and complex system of social relations and of material and symbolic transferences, that constitutes a relevant analytical unit to understand the transition to adulthood in its various manifestations' (Pappámikail, 2004: 113).

2.13 Therefore, the life course perspective is an indispensable analytical instrument for the study of the transition to adulthood in countries with these characteristics, that is, in a context of transitions to 
adulthood simultaneously from, to, with, and within the family. To sum up, quoting Pais, an analysis of life courses should include two different ingredients: individual trajectories and social structures, because 'youth identities are not only associated with individual life stories - that is, individual trajectories - but also trajectories that are socially, structurally and historically determined.' (Pais, 1993: 73-74).

\section{Data and methods}

3.1 A variety of data was used to demonstrate the usefulness of both macro and micro data to the comprehension of the home-leaving process, particularly in a familistic society. As we will see later in this article, this process of obtaining residential autonomy in early adulthood is a paradigmatic example of the heterogeneity of the transition(s) to adulthood in Europe.

3.2 To demonstrate this striking heterogeneity in indicators of the home-leaving process, as well as the age norms and practices in transitional events, data from the cross-sectional 2006 European Social Survey $2006^{[2]}$ was used. Although it does not provide longitudinal data, one of the rotating modules is concerned with 'The Timing of Life: the organisation of the life course in Europe' and provides very good, up-to-date and comparable information on life course trajectories. Three types of data were collected. First, data was collected on the year (and age) for each of the first events in the individuals' professional, conjugal, residential and parental careers ${ }^{[3]}$. Regarding these variables, the mean age for these events was the most used statistical measure. Secondly, data was also collected on the age norms (ideal, early and late) for the following events: 'becoming an adult', 'leaving full-time education', 'having sexual intercourse', 'starting life with a partner, without marriage', 'getting married', 'becoming a mother/father' and, the most useful of all for this particular analysis, 'too old to be still living with parents' (age). In this case, besides the average ages, the qualitative age norm responses (such as not approving of a certain event or not recognizing the existence of an ideal, early or late age for a certain event) were also analysed ${ }^{[4]}$. Finally, data was also collected on the importance of various events in one's life to becoming an adult: 'having a full time job', 'having lived with spouse or partner', 'having become a mother or father', and 'having left the parental home ${ }^{[5]}$. In these indicators, the sum of the percentages of the two levels of attributed importance (important and very important) was analysed.

3.3 Taking into account the heterogeneity found in Europe and the specificity of the Portuguese case, analysed here, different data was analysed. As it is a primary source, certain aspects deserve clarification. For well over a decade (1992-2007) there was only one programme that encouraged the residential autonomy of young people through the rented housing market, that is, through the most suitable mechanism for fulfilling the mobility and flexibility needs of young people. This was the 'Rental Incentive for Young People Programme' (IAJ) of the then (2005) National Housing Institute. This programme aimed to 'regenerate the housing market' and provide 'a real alternative to meet the housing needs of young people embarking on a new phase in life' (Government internet page on youth). This programme had specific and very particular characteristics, e.g. the numbers were not fixed at a specific level, there were no territorial quotas, there was no implicit or explicit precedence given to couples or families over individuals and, most of all, it promoted the rental market. At the time, the closest thing available was a programme created in 1996 with the primary goal of creating accommodation on the housing market of the capital, with low prices and the focus exclusively directed at young people. However, this only covered Lisbon and promoted homeownership, which was already greatly valued by family cultures.

3.4 Nonetheless, for access to this programme, there were certain requirements. The beneficiaries of the IAJ had to have been working ${ }^{[6]}$ for at least a year, and could not be more than 30 years old ${ }^{[7]}$. The $96-$ question survey was completed in 2005 (the last year of this programme) by 120 IAJ programme beneficiaries that had left home to live without a spouse/partner or relatives, in the waiting room of the IAJ administrative services in the National Housing Institute. Non-family living was a prerequisite of the research carried out at the time ${ }^{[8]}$ but was also the most representative sub-sample, as more than half of all the IAJ applicants were living alone (without partners, children, other relatives or flat mates). This reflected a huge increase since 1992 (from 22\% ( $n=1166)$ to $53 \%(n=15703)$ in the applications and renewals $)^{[9]}$.

3.5 Of the 96 questions on demographical and social characteristics: the decision to leave and the process of leaving the parental home; the application to the IAJ and the state's responsibilities; life projects; family relations; sociability and sexuality; 'home' and, finally, conjugal autonomy, only some were used for the present discussion. The questions included are connected with all the dimensions mentioned but relate to specific questions on, namely: the material and financial aid actually given by parents at every point in the home-leaving process (whether education-related or not); the fairness of, and a comparison with, the financial aid commonly given by a bridal couple's parents; the frequency of the material and financial aid given during the time of the residential autonomy gained; ideas on future conjugal involvement; the currently preferred residential situation (conjugal or non-conjugal); the moral judgments of the father and the mother concerning the non-family living (relating to responsibility, immaturity, financial changes, conjugal preferences); the importance of foreknowledge of the IAJ in the decision to leave home and rent a flat; the importance and justification of the existence of the public housing programme for the parents' acceptance of the non-family living; the level of importance of eight different life events in the personal fulfilment of the young adult and his/her parents (according to the young adult); emotional changes in the relationship between the young adult and both the father and the mother; the time spent at the parents' and the person's own home; the perceptions of autonomy during a conjugal relationship (if applicable); and, lastly, the 
3.6 These variables will be used to argue against some of the preconceptions, in traditionally familistic countries, about the eccentricity of non-family living in early adulthood. On this point, the analysis will be descriptive.

\section{Leaving home, transition(s) to adulthood and European heterogeneity}

4.1 It seems useful to open the section with the statement, 'In a time of overall social and economic convergence in European countries, it is hard to find social indicators with such striking differences among EU countries as those related to leaving home' (Aassve et al., 2002: 259). In order to demonstrate these striking differences, it is important to present the significance of several transitional events in the attainment of adult status in European countries, and the distinction between generations in the matter. This analysis reveals the cultural norms of the ingredients for a 'successful" transition to adulthood.

4.2 With regard to the overall importance attributed to different events in the transition to adulthood, to attain adult status - considering the whole sample (different ages, countries) - it is noticeable that having a full time job is in fact the most important marker of adulthood. It is the event that is most frequently considered important or very important for an individual to be recognized as an adult. Secondly, parenthood presents the lowest percentage of individuals who think that being a parent is neither important nor unimportant for an individual to become an adult (while conjugality presents the highest percentage in this category). Parenthood has not lost its important role in the transition to adulthood, being the ultimate symbol of taking responsibilities for others. This characteristic is shared with the life-cycle perspective.

4.3 'Leaving the parental home" is considered important or very important in $39.7 \%$ of the cases. The most striking conclusion of this data is that to have lived with a partner or spouse is ultimately the least important indicator of adulthood, as it is the event that in only $35.3 \%$ of the cases is considered important or very important to reach adult status. The proximity between the importance attributed to residential autonomy per se and conjugality as markers of adulthood may indicate that these two transitional events are, in some cases, evaluated as if they were one and the same (because they are also lived as a single transitional event). ${ }^{[10]}$

Table 1: The importance of transitional events in the attainment of adulthood in Europe

\begin{tabular}{l|c|c|c|c|c|} 
& $\begin{array}{c}\text { Not at all } \\
\text { important }\end{array}$ & Not important & $\begin{array}{c}\text { Neither } \\
\text { important nor } \\
\text { unimportant }\end{array}$ & Important & Very important \\
\hline Residential autonomy & 16.4 & 28.0 & 15.9 & 31.6 & 8.1 \\
Full-time job & 12.0 & 22.8 & 15.9 & 37.2 & 12.1 \\
Conjugality & 17.1 & 28.4 & 18.5 & 29.1 & 6.9 \\
Parenthood & 17.3 & 23.1 & 14.7 & 30.6 & 14.2
\end{tabular}

Source: European Social Survey 2006

4.4 European heterogeneity is illustrated by the following figure. It demonstrates the dichotomy of high regard for responsibilities towards others (familistic or relational indicators, more associated with the normal biography) versus high regard for the responsibilities towards oneself (individualistic or personal indicators, much more associated with the choice biography). As we can see in Figure 1, the regard for conjugality as an important marker of adulthood is accompanied, with few exceptions, by the regard for parenthood. That is to say, there is a clear linear relationship between them: when conjugality is considered important, so is parenthood, and when conjugality is not considered important to the attainment of adult status, neither is parenthood (this is especially true for processes involving low regard).

4.5 The regard for conjugality (and parenthood) is also related, negatively but linearly, to that for residential autonomy as an important marker of adulthood. Therefore, on the one hand, we have southern and postsocialist countries like Bulgaria, Ukraine, Russia and Portugal, where two exceptional tendencies occur: residential autonomy is the least valued indicator of adulthood and parenthood is the most valued. On the other hand, all other countries consider either residential autonomy (the Scandinavian countries) or a fulltime job as the most important marker of adulthood. The effect of ascertaining these differences is the accumulation of certainties about welfare states and family cultures, which often allow comprehension of the phenomenon.

4.6 The countries that give more importance to these two transitions (such as Bulgaria, Ukraine, Russia, Portugal, Poland, and Cyprus) tend to devalue residential autonomy per se, considering it the least important event for the attainment of adult status ${ }^{[11]}$. These countries, with the exception of Cyprus, are also the only ones to consider parenthood the most important marker of adulthood. With the exception of these countries, where parenthood is considered the most important marker of adulthood, and of Sweden, Norway, Finland and Denmark, where, as already mentioned, residential autonomy is considered most important, all countries consider having a full-time job the most important event in the transition to 
adulthood and the attainment of adult status. These countries form two different sets of cultural norms on adulthood. If the second set of countries is coherently Scandinavia, the first is not geographically or historically coherent. With respect to cultural norms on adulthood, Portugal presents different patterns from those of the rest of southern Europe, by demonstrating more traditional patterns ${ }^{[12]}$.

4.7 Moreover, we ascertained that in Portugal there is the tendency to attribute more importance to each of the transitional events in the attainment of adult status than in Europe in general. With the very relevant exception of the residential autonomy marker, more than half of the sample considers the traditional transitional events important or very important for an individual to be considered an adult. This is particularly evident in the case of parenthood, while conjugality and a full-time job are attributed identical levels of importance. That is to say, the well-known tendency of some countries (including Portugal) to attribute importance or high importance to the constructs surveyed is not valid in the case of residential autonomy as an important marker of adulthood. This demonstrates how it is really given less value in comparison with other countries.

Figure 1: Important and highly important transitional events in the attainment of adulthood, by country

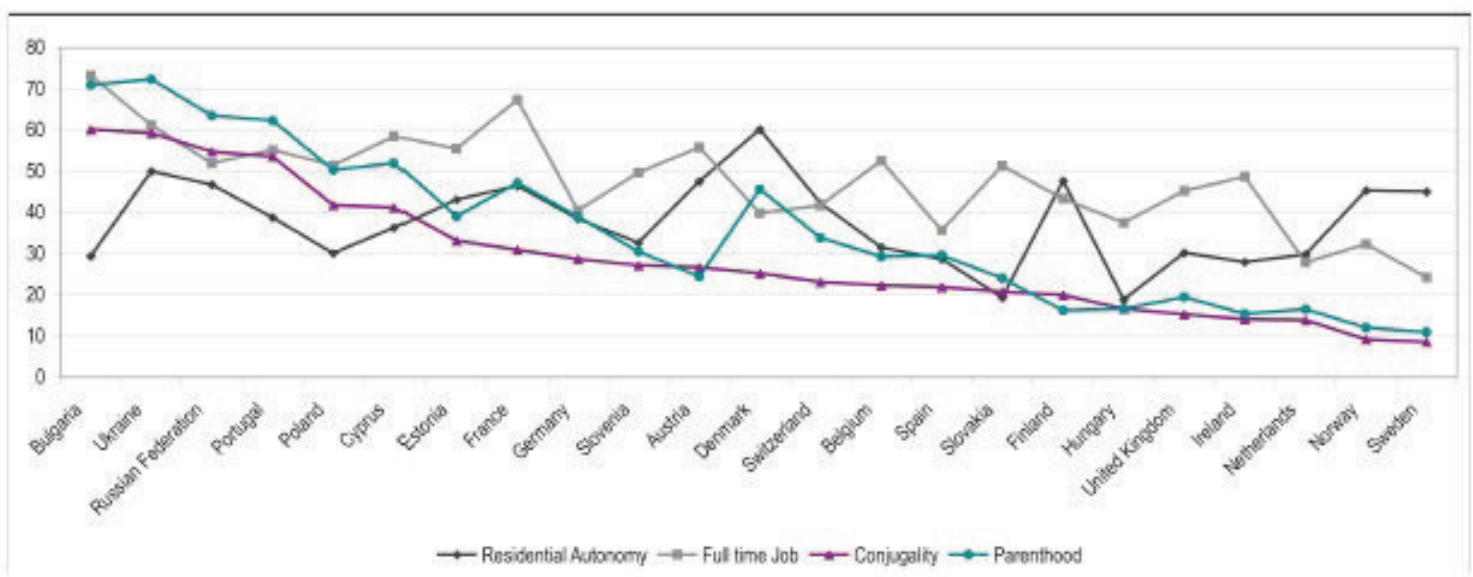

Source: European Social Survey 2006

4.8 'Choice biographies" or 'do-it-yourself" biographies (Beck-Gernsheim, 2002) are a tendency that was empirically and theoretically evident among the cohorts born in the 70s and later. How intense is the cultural-norm heterogeneity between the different cohorts?

4.9 The attribution of importance to each of the events in the transition to adulthood presents variations throughout the age groups and these conceptions have the potential to indicate inter-generational divergences on the recognition of what it is to be an adult nowadays. In the figure that follows, it can be seen that as age increases, so does the importance attributed to all the markers of adulthood considered in this analysis, with the exception of residential autonomy. That is to say, the assumption that adulthood can be measured by three or four criteria is more widespread among older individuals than the younger ones, who tend to evaluate adulthood in a more de-standardized approach. Nonetheless, as we have already seen in the previous analysis, in the general population, Portugal presents that kind of structured view of what it is to become an adult.

4.10 We can also see that the apparent stagnation in the importance attributed to residential autonomy throughout the generations is responsible for hierarchical differences concerning the importance of these four markers of adulthood, between generations. Thus, residential autonomy is a marker of adulthood that only assumes relative significance in the age group that best represents the 'contestable adulthood' already mentioned (aged 19-34) and in the even younger generation. While other indicators lose importance, this indicator gains autonomy in its rating and maintains its effective importance, increasing its relative importance throughout the generations. On the contrary, older respondents tend to associate conjugality and residential autonomy, as these were two inseparable events in the transition to adulthood. This analysis allows us to state that residential autonomy, as an indicator per se, has become a contemporary symbol of a de-standardized transition to adulthood.

Figure 2: Important and highly important transitional events in the attainment of adulthood, by age Group 


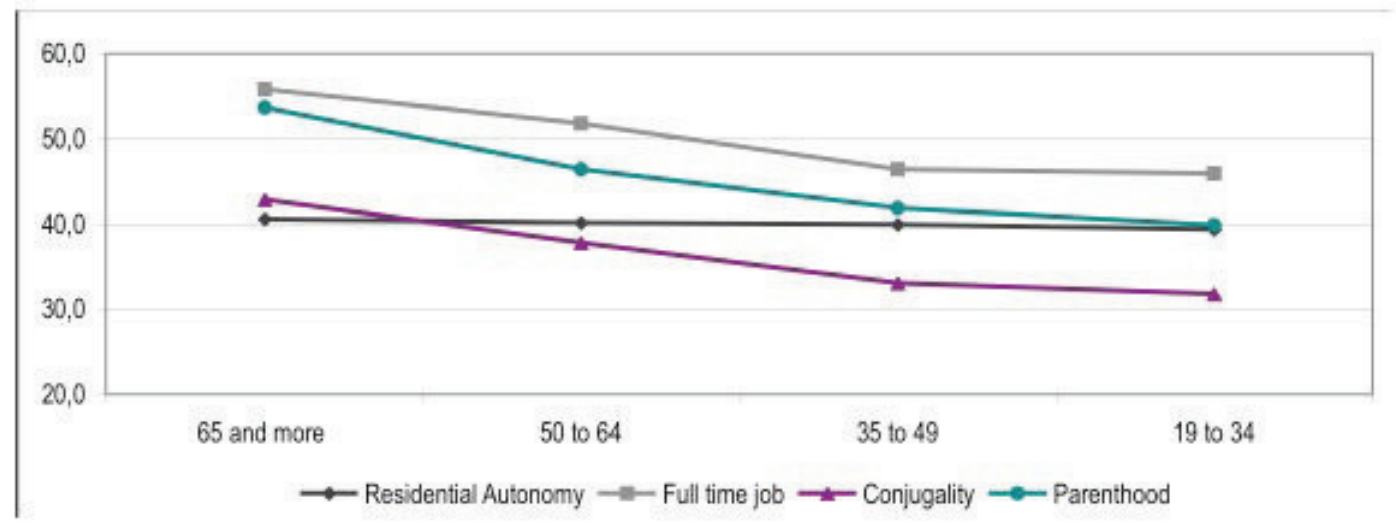

Source: European Social Survey 2006

4.11 In the cultural norms of what it takes to be an adult, Portugal, along with other (mostly post-socialist) countries, presents overall traditionalist and structured views, similar to older generations in the whole sample, on the subject (importance attributed to all events but less to residential autonomy per se). But how does the importance attributed to different transitional events actually reflect the sequence of the timing of the events? The following data helps to answer that question, for it presents the timing of the objective experiences considered in the literature and statistical data as important markers: 'being financially independent, having completed school, having a full time job, having the capacity to support a family, having left the parental home, getting married and having children' (Billari, 2005; see also Molgat, 2007: 498). Galland $(1984,1991)$ also argues that the three most important transitional events are the residential one (from parental home to a home of one's own), the professional one (finishing school and entering the work market) and the relational one (from being single to living in a couple and family) (in Molgat, 2007: 495; see also Zittoun, 2002: 193, Oinonen, 2004; lacovou, 2001:1 and Billari, 2001: 120).

4.12 Although transitional events to adulthood have become more reversible and extended in time, we can still see what appears to be a linear order within the transitions ${ }^{[13]}$. This is a simple but important statement that, at least with regard to the sequence of the first events in each of the important careers (professional, residential, conjugal and parental), illustrates the 'persistence of the standardized life cycle' (Elchardus and Smits: 2006). This persistence is much more evident in the 'lived' (Billari, 2005) lives rather than the 'experienced' (Billari, 2005) ones which were already analysed previously.

4.13 Thus, work experience is the first 'adult experience', and leaving the parental home seems to be an immediate consequence of that. Conjugality (with or without marriage) and parenthood occur later in life, after a period of at least three years of residential independence. Besides this general tendency, there are relevant differences between countries, some of them seen in the next figure. It shows that there are only two exceptions to the chronological order previously described for all the countries. The only two countries that do not follow the chronological order (first job experience, first residential autonomy from parental home, first conjugal cohabitation experience, first marriage, and first child) are Estonia and Sweden ${ }^{[14]}$.

4.14 As far as the overlapping of transitions is concerned, we can see that the two pairs of transitional events that overlap the most (independently of the average age in which that happens) are: the first experience of conjugality with marriage, and marriage with the birth of the first child. The first case of overlapping is more frequent in the Mediterranean area (Portugal, Spain, and Cyprus) and Eastern and Central European countries (Estonia, Poland, Ukraine, Russia, Bulgaria, Slovakia). These are, therefore, the countries that tend to exclude conjugal cohabitation from their life course, making it coincident with and a consequence of the moment of marriage. Portugal thus remains the only southern country (within the ones considered, i.e. excluding Italy) where both the cultural and structural views on adulthood are traditionalist. The second case of overlapping mentioned is more frequent in Denmark, Norway and Sweden, that is, Scandinavian countries, where it is after or due to the birth of the first child that conjugal cohabitation ceases and is transformed into a more institutionalized union: marriage. In this case, marriage does not coincide with cohabitation per se but it is the desirable context for parenthood.

4.15 In relation to residential autonomy, even if temporary and/or reversible, we can see that in central and southern European and post-socialist countries it occurs later. Spain is the country in which the average age for leaving the parental home is highest, at 23.4 years of age. The countries that follow are Belgium, Poland, Hungary, Slovakia, Slovenia, the Netherlands, and Portugal. In these countries, the average age at which individuals first leave the parental home is close to the average age for the first experience of cohabitation (with or without marriage, with the exception of the Netherlands). Thus, even when this autonomy occurs, it is experienced for a very short period, being almost immediately substituted by conjugality.

4.16 To sum up the heterogeneity of the relationship between the importance attributed to different markers of adulthood (conceptions of adulthood) and the ages at which these transitional events occur (practices of adulthood), particularly residential autonomy: 'in countries where young people typically leave home late, 
they are much more likely to leave home with a partner, while in countries where home-leaving typically occurs earlier, it is much less common to leave home as part of a couple. (...) A good deal of the intercountry variation in the age at leaving home may be accounted for by the greater propensity in Southern countries to leave home to live with a partner.' (lacovou, 2001: 8-9). In fact, the age at which departure from the parental home occurs is strongly associated with the destination, that is, if it is a partnership-related departure or not (lacovou, 2001: 5).

Average ages at first events in the transition to adulthood, by country[15]

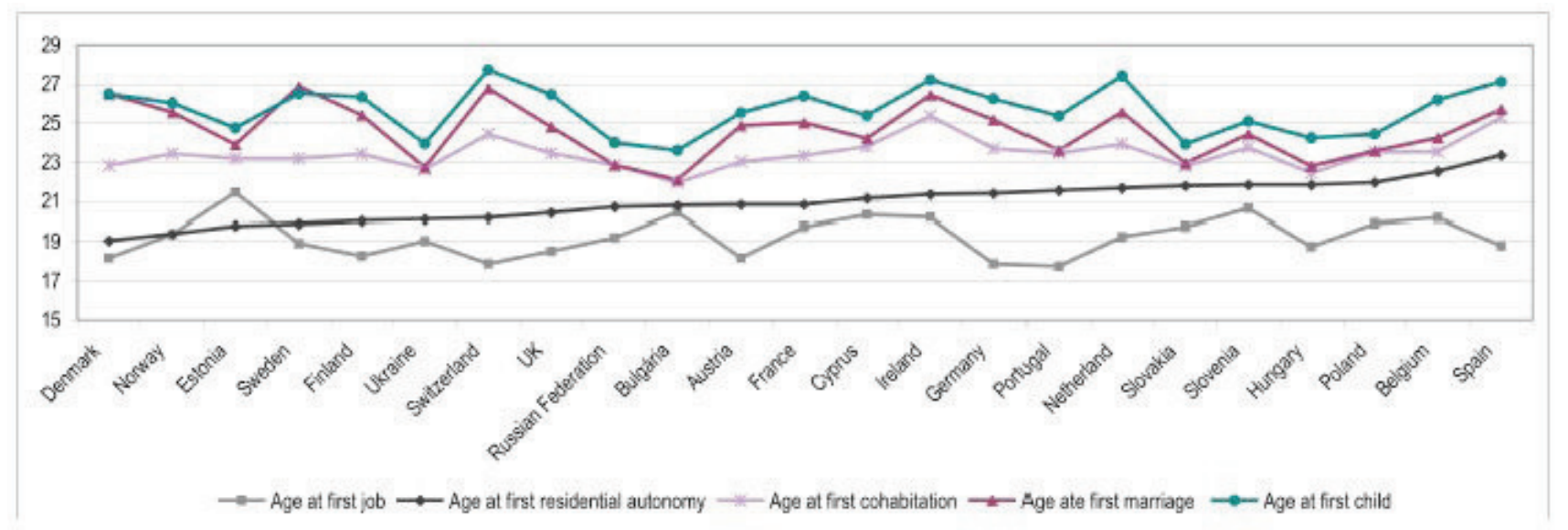

\section{Non-family living in a familistic society}

5.1 Secondary sources of data from the European Community Household Panel ${ }^{[16]}$, the 2006 European Social Survey and other surveys providing information on the life course are extremely useful in ascertaining the specificity of Portugal, particularly in what regards the process of leaving the parental home, and in defining 'typical' and 'atypical' national trajectories from the parental home to autonomous residence. Nonetheless, they do not help us understand how far visible life courses (desired, described, or lived) are constrained by cultural and age norms or by national structural features. They do not provide evidence, for instance, that contributes to an understanding of how these exceptions to the rules are normally lived. What do they represent and how do the statistics hide them? Frequently, these analyses only reify preconceptions based on simplistic classifications of a nation's (or set of nations') welfare-state-related, or just geographical, characteristics, creating obstacles to social change.

5.2 In order to answer to these questions, an atypical path out of the parental home is put in perspective. But first: what are the characteristics defining this path as the exception and not the rule?

5.3 First, leaving home to live alone or as a couple in a rented house or flat is quite rare in Portugal. Even when we include the older generation with low levels of mobility (and mobility needs), owner-occupied dwellings represented $3 / 4$ of the total in 2001 (Norris and Shiels, 2004:10). This is true even when we consider that the number of dwelling units constructed annually per 1,000 of the population is one of the highest in Europe (Norris and Shiels, 2004: 14), because the trend is for the percentages of owner-occupied dwellings to increase by about $10 \%$ every decade (Norris and Shiels, 2004:42). The rented housing market is rather poor and waning.

5.4 These characteristics are consistent with the apparent specificity of southern housing markets, in four aspects: 'high rates of home ownership coupled with little social housing, the significance of secondary housing, the relationship between access to housing and household cycles, and the role of the families in housing production' (Allen et al., 2004: 15). These characteristics are shared by Spain, Greece, Italy and Portugal and contrast with those of Central European and Nordic countries (Allen et al., 2004).

5.5 On one hand, it is stated that leaving home at an age that is in accord with modern life styles and aspirations about mobility, independence, and personal development, under conditions that offer access to adequate accommodation, is a natural process of growing up and should be recognized as an important social right... [and] housing policy should be revised towards an increase of opportunities and freedom of choice' (Emmanuel 1989), European Community in White, 1994: 86). On the other hand, although it is assumed that the creation of conditions for the mobility of the population is necessary, that the access to habitation is one of the most important means towards that and, finally, that the rental system is the appropriate instrument par excellence (Portuguese National Institute, 1995), the rental system is, and already was in 1995, practically lifeless and completely inadequate for young adults' needs. This mismatch could be described in the following terms: 'one source of potential instability is the tension between the standardized life-course program and the claims for individualization and biographization, which are increasingly institutionalized as a legitimate and even normatively required way of life' (Kohli, 2007: 257). That is to say, as far as residential autonomy in early adulthood is concerned, there is great haziness between European guidelines on this matter and the reality in Portugal.

5.6 Are these characteristics important enough to explain the postponement of leaving the parental home, or will the 'long-term cultural continuities, with emphasis on the strength of inter-generational ties within 
5.7 Secondly, housing policies are in general very few. Housing policies that aim to activate the rental market are even more so. Nonetheless, the young adults mentioned above found a niche in the housing market, and had access to the IAJ as a second source of income. This is a very rare resource in Portugal, which allowed young adults to count on a public policy to widen their opportunities for transition (to adulthood) and mobility (in their life courses), through improvement in their lives and opportunities for independence (that is, from the family). According to the report 'Youth in New Europe' (Eurobarometer, 2003), Portugal is the country with the second highest dependency on the family, with more than $40 \%$ of young adults aged between 15 and 30 having their primary source of income in the family (relatives or partner). That also makes these young adults the exception to the rule, for their primary source of income is, in $93 \%$ of cases, a regular job.

5.8 The third atypical characteristic is the first to be presented, which is leaving the parental home without immediately or very shortly starting any kind of conjugal union.

\section{Independent living in familistic societies: misconceptions and counterarguments}

6.1 It has been stated in this article that there are (i) misconceptions about the functioning, function and, most of all, adaptability of intergenerational support in familistic societies and (ii) preconceptions about non-family living in early adulthood in such societies. Together they lead, as we will argue in the final remarks, to the weakening of the already scarcely available housing programmes centred on the individual (and not families), particularly the young adult. In the hope of contributing to these issues, the next section of this article will present counter-arguments mainly based on the primary source previously described, as a response to these misconceptions and preconceptions (briefly presented in the form of statements quoted from official reports or research analysis).

6.2 Two sets of argument are generally used, the first attributing responsibility for the postponement of the change of residence to structural features, and the second attributing responsibility to individuals' hedonistic choices - taking individualization theory and the 'choice' biography too far and, ultimately, making the inadequacy or insufficiency of youth policies less visible.

6.3 a. 'Not being able to afford to move out' is the most frequent subjective reason for young adults to be living with parents longer than in the past, according to European respondents aged $18-24^{[17]}$ (Flash Eurobarometer, 2007:24). This is a structural argument that places responsibility for the extended transitions to adulthood, at least as regards the residential autonomy career, on the relationship with other institutions, particularly the most important in the transition to adulthood: the (entry into the) labour market and the characteristics of and attitudes towards the housing market and the family.

6.4 The financial instability of young adults is, thus, often considered the strongest predictor (if not the only one) for a weak tendency towards non-family living in early adulthood. Moreover, as Aassve et al. stated with reference to the transition to adulthood in general, 'in the Southern European model, employment and earnings are particularly important, which is consistent with the weakness of the welfare state' (Aassve et al., 2002: 273). On the other hand, Billari also argued that 'any study considering only demographic events or only educational and work events is incomplete from the perspective of a transition-to-adulthood approach' (Billari, 2001: 121). Accordingly, discussion on certain other strong explanatory factors will now be presented.

6.5 a.1. The most relevant external or conjunctural feature implicit in the statement highlighted is the extension of educational careers which, not necessarily but very frequently, prevent young adults from engaging in more regular and/or full time work. This educational variable can show us how non-linear the relationship is between income and residential autonomy. Taking Portugal as the appropriate example: although it is one of countries in which the percentage represented by the regular job in the main source of income is identical to the European mean ${ }^{[18]}$, i.e. $44.1 \%$ (Eurobarometer, 2003), it is simultaneously the country with the second highest percentage of young adults stating that 'they can't afford to move out the parental home': 62\% (Flash Eurobarometer, 2007:24).

6.6 Combining this data with the low tendency in Portugal to have a full-time job and, simultaneously, be enrolled in the higher education system, it may be said that remaining in education during the age at which young adults could be expected to leave the parental home is not the main justification for a high percentage of them stating that 'they can't afford to move out'. It could also be argued that this means that, if correct, this statement reflects - more than structural reasons - cultural norms based on specific conditions that are behind the young people's 'rational choices'. Michael et al. have already demonstrated that 'the relationship between income and the propensity to live alone is not linear' (1980:49), as could be expected.

6.7 a.2. In this case, one of the two most important hidden cultural norms is the tacit relationship between the high value given to home-ownership and a weakened and inefficient rented housing system. On one hand, even among the younger people, there is a high value placed on home-ownership (despite the high prices and the rigid stability requirements for a bank loan) and a general rejection (in all generations) of the idea of renting a house or flat instead of investing in an asset. Together with the inefficient and inflated rented housing market, this makes renting accommodation a very unattractive option, both from the cultural 
6.8 Thus, the statement that they 'can't afford to move out' may in this case (and perhaps in many others characterized by the same cultural and housing circumstances) mean exclusively that they cannot afford to buy a house or flat. This non-affordability in relation to buying a house is certainly not a specific characteristic of Portugal, or even the southern European countries with which it shares certain housing characteristics. It is the cultural equivalence of 'moving out of the parental home' and 'becoming a homeowner'. It could be said that, when comparing the countries and facing such cultural norms, this feature may be the characteristic that represents the shared denominator in the explanation of the postponement of leaving the parental home.

6.9 Awareness of the subjective and implicit equivalence mentioned, between 'leaving the parental home' and 'becoming a home-owner', allows us to put housing policies aimed at revitalizing the rental system into proper perspective. In Portugal (as could happen in other so-called familistic societies), family support (financial and material) is guaranteed with or without the co-existence of public (particularly housing) policies. In other words, family support does not suffer from the interference of housing allowances. If any, the interference is positive, for, in this sample, $3 / 4$ of the individuals already knew the conditions offered by the IAJ when they made the decision to leave the parental home. In fact, $2 / 3$ of them argued that this knowledge actually facilitated both the decision to leave home and the parents' understanding of and support for the decision (considering it legitimate).

6.10 Moreover, leaving home (even alone) does not constitute a gap in the financial and material help, but a continuity of the standards practised so far. In the opinion of the young adults, with respect to the decision to leave home, most parents did not take either of the opposing stances: 'It is time for my son/daughter to be totally independent financially,' or 'This is the time for us, the parents, to help our son/daughter financially.'

6.11 Nonetheless, this "informal" help is clearly not enough. We thus conclude that it is in fact the nonexistence of public welfare policies, in particular those aiming to revitalize the rented housing market, which is actually preventing young adults from leaving the parental home sooner to live alone. The often claimed relationship of material, financial or emotional dependency of young adults on their parents, taken as a characteristic of familistic societies, would not be no hindrance to leaving the parental home. In fact, it is an ally in the pursuit of such a goal - that is valid even in cases of non-family living.

6.12 a.3. The other important tacit feature, quite closely related to the previous one, is the traces of the Catholic tradition, according to which, in the case of a wedding, the couple's parents are implicitly considered responsible for the costs (even if it is solely civil marriage) and, to no small extent, for a contribution towards the creation of the new family home. Getting married (the most common way to start a union in Portugal) can actually be less expensive than leaving the parental home non-conjugally, on account of the secondary sources of income. Besides sharing the expenses of the household, the two sets of parents make a financial investment in them through the wedding ceremony. That investment reverts to the newly-weds, through the wedding gifts.

6.13 That said, it almost seems that the family of origin tends to take the place of the inefficient welfare state, particularly with regard to improvement in the couple's living conditions. However, in fact, family has this function independently of the circumstances: with or without a conjugal union or the assistance of the welfare state. Family support networks do not cease to function just because young adults decide not to get married or to live with a partner (right away). It has been demonstrated that, among young adults who live outside the context of the couple, there is frequent monetary, material or moral support that, for both the parents and the young adults, is very natural. Young adults do not appear to be disturbed by this, as the help is viewed as being just as 'normal' as the investment that parents make in weddings (those of their siblings or the children of other families). Help that comes after the young ones have left home is even more acceptable when it is material (monthly groceries, dinner or lunch invitations, clothes, etc.) rather than strictly monetary. Furthermore, in this survey, at the moment of leaving the nest, around $30 \%$ of the young adults took their room furniture and equipment and received new kitchen appliances, and around 15\% received new furniture and/or the first payments of the rent as gifts.

6.14 So, even when there is no immediate family project and there are housing allowances from the state (in this case, the IAJ), the family still maintains the intergenerational support relationship with the young adult. Intergenerational support networks are not dependent on cultural and age norms based on 'family values'.

$6.15 \mathrm{~b}$. Living alone or with friends is often considered to be an alternative and experimental course of life. Simultaneously, prolonging the stay in the parental home until a late age can also be considered a strategy to avoid financial obligations and to increase opportunities of leisure and consumption. These interpretations of home-leaving process are very frequent in a familistic society such as Portugal.

6.16 This justification is an 'individualized' responsibility attributed to the young adults' intentions and shortterm plans, attaching a hedonist interpretation to their actions. There is some tendency in the youth studies in this southern European country to consider every life event other than the conjugal or parental ones as experimental and alternative, or even irresponsible and hedonist. Both staying at home until a late age and leaving home to live alone or with friends is allegedly a sign of immaturity and a life of amusement: mere 
6.17 Non-conjugal residential autonomy is often seen and analysed as if it were an 'alternative' lifestyle, a side effect of the postponement of conjugality, the embracing of leisure and irresponsibility. In short, it is seen as an objection to conjugal commitments and a eulogy of individualism. This process ultimately attributes the same cause to different effects, which is tremendously ineffective both for our comprehension of the phenomenon and any contribution to evidence-based policy-making and mobility and flexibility-related youth policies.

$6.18 \mathrm{~b} .1$. What the data allowed us to verify, on the contrary, was that non-conjugal residential autonomy is not seen or felt by these young adults who live alone and are 'sponsored' by the state as an objection to or the lack of a desire for conjugality. This generation does not see individuality and conjugality as a dichotomy but as two different stages in the life course. Accordingly, two-thirds of the sample was living alone by pure choice, but $24 \%$ would prefer to be living with a partner. On the other hand, with the exception of the $35 \%$ who had no conjugality plans or concrete projects and the $9 \%$ who chose not to answer this question, all these young adults planned some kind of conjugal co-residence (marriage in church - 12\%, civil marriage $-3 \%$, informal civil union before marriage $-24 \%$, the latter with no marriage plans $-17 \%)^{[19]}$. They do not underrate conjugality as a life project or source of personal fulfilment: the percentages of young adults who think a conjugal union (marriage or an informal arrangement) has unfavourable consequences such as the loss of personal autonomy, greater dependence on the other person or greater dependence on the part of the other person, are also minimal (around 6\%).

6.19 With respect to the intergenerational expectations of this non-family living in early adulthood, this living alone is not considered the most important marker of adulthood, not even by these residentiallyautonomous young adults, and is not considered the least important marker of adulthood by their parents (in the young adults' point of view). However, it is the life project that provides the most evidence (and the highest percentage - a difference of almost $20 \%$ in the attribution of importance, with parents giving less importance) of a generation gap in conceptions of adulthood in Portugal. Even so, overall and for these young adults' families, non-conjugal residential autonomy is not a source of conflict or disagreement. Actually, on most occasions, leaving the parental home does not even seem to cause interference in the quality of the relationship between parents and young adults (74\%). When it does, it is actually in the sense that the parents seem to be more, and not less, concerned about their children. This is especially true for the mothers.

6.20 b.2. Furthermore, youth autonomy is not as dependent on the concept of hedonism as is often suggested in the literature on this subject (especially in familistic societies). Thus, one must not interpret being responsible for oneself as the opportunity to be irresponsible. Indeed, parents rarely considered nonconjugal residential autonomy as a symbol of immaturity or the desire to live a more irresponsible life (only around $9 \%$ ). The shift in the lives of these young adults is precisely in the other direction: the great majority spend more time at home than they did when they were living with their parents, and also feel that the kind of life they lead is much more responsible than the one they led when they were living with their parents. Thus, non-family living in early adulthood is not seen as an opportunity or requirement for an 'irresponsible and unstable' lifestyle but, in many cases, as we have shown, precisely the contrary. In this context, nonfamily living is a symbol of a 'choice biography', not an unstructured 'risk biography'.

6.21 In relation to the argument that young people in these societies do not leave home in order to keep their leisurely lifestyle, it must be highlighted that southern European countries do not share a framework of common cultural and age norms. Thus, Portugal presents the European average percentage for young people who state that the main reason for not leaving home sooner is that they 'want to have home comforts without responsibilities' (Flash Eurobarometer, 2007:24) - along with all southern European countries except Italy (above average). These average values are not consistent with the idea that the greater the tendency to try to escape responsibilities and have a leisurely life, the later a person leaves the parental home.

\section{The rise and fall of independent living in early adulthood: final remarks}

7.1 Such as 'past scholars were not looking for the individualized, subjective, complex transitional experience' in the 1960s (Goodwin and O'Connor, 2005: 217), current scholars are not looking for them in so-called familistic societies. Over-concentrating in macro-processes and producing typologies of European countries have discouraged the analysis of the individual experiences and specific circumstances that frame them.

7.2 In this article, we have addressed some of the preconceptions concerning familistic families. On one hand, parental financial and/or material support for young adults was expected, but not an unconditional one. In so-called conservative societies, age and cultural norms concerning conjugality were expected to affect the type and amount of help given to young adults: a reward for the conjugal paths towards adulthood and the disregard of non-conjugal alternatives. However, an unconditional (neither immediately conjugal nor home-owning paths) type of support is quite striking and visible. Strong cultural and age norms regarding the transition to adulthood do not predetermine or constitute obstacles to choice biographies, that is, in this case, biographies diverging from the norm (or normal biography). This means that 'long-term cultural continuities, with emphasis on the strength of intergenerational ties within societies' (Aassve et al, 2002: 260) demonstrate great adaptability to the individualization of the life course. 
7.3 Unfortunately, this adaptability is currently underestimated but, on the other hand, it is greater than that demonstrated by welfare state policies. This should be taken into account in the policy-making process. That is to say, not only can different institutionalizations of the life course co-exist (public policies, on one hand, and intergenerational and informal family support, on the other) but that co-existence can in fact be one of the best sponsor of paths of individualisation and independence. Evidence of such fruitful coexistence is the flexibility provided in the process of leaving the parental home, as described above. At the time, the individuals surveyed were in the process of choosing de-standardized courses in their lives, taking new roads, and showing avant-garde attitudes in their way of dealing with the desire to live independently (of their parents or a new family). This was possible not only due to their participation in the labour market, but also the support of their family and the incentive offered by the state. This allowed an increase in nonfamily living in early adulthood, not to the point where it would become mainstream but to where it could be a real alternative to postponing leaving the parental home until the expected consensual union.

7.4 When the programme began in 1992, the number of IAJ beneficiaries was only around 1160 (official data provided by the National Housing Institute), which represented a mere $4 \%$ of the country's young adults aged 20 to 30 living alone. Furthermore, a decade later, there were approximately 70,000 young adults aged 20 to 30 living alone in Portugal, among whom around $22 \%$ were already included in this programme $(\mathrm{N}=15703)^{[20]}$. This positive development towards a path of successful individualization in residential autonomy - though there was still a need to adapt the criteria for access to the programme - was interrupted. Whether it was the result of misinterpretation of this success of modernity or disregard for this non-family living, only a political assessment can clarify.

7.5 A different housing programme abruptly replaced this programme. The transition between them made the differences in the criteria and the number of beneficiaries very clear ${ }^{21]}$. Thus, if some of the criteria provided more flexibility (e.g. in allowing non-related friends or flatmates to share the rent and the benefit or in providing special incentives in the historically run-down areas), most of them, including the most important, did not. The latter criteria were responsible for a drop of $60 \%$ in the total amount dedicated to this programme and approximately $50 \%$ in the number of beneficiaries (when 2005 and 2006 are compared).

7.6 What were these changes and what were they based on? The whole concept behind all the changes was the standardization of the life course. In particular, there was a decrease in the number of years during which one could apply for the incentive, this maximum number of years had to be consecutive, involving the same house, and there was a limitation on the number of rooms in the house (disadvantaging young adults who wanted to live alone, for there is a very limited supply of bedsitters or one-bedroom units). Most important of all, for each area (urban, rural, etc.) the maximum rent was defined. Instead of analysing the possible effort of each individual (based on a calculation between rent and monthly income), a rent limit was defined. Now, to be able to apply for this incentive, young adults have the difficult task of finding dwellings costing up to specific rents rather than those with rents defined by the market itself.

7.7 Instead of taking advantage of the necessary revitalization of the rented housing market to the profit of flexibility in the young adults' lives, the programme seemed to want the young adults to push down the inflated prices of rented accommodation. Consequently, this became a risk biography rather than one of choice, in the sense that any unpredictable change in their life course (sharing the house with a friend, entering a consensual union, changing the location of the job, etc.) could mean the irreversible loss of the incentive and, often, the inability to afford a flat without parental help. Ultimately, this could force them to return to their parents' home, to hurry into a consensual union and/or home-ownership or, in the most worrying cases, to come very close to homelessness.

7.8 This case study allows us to reaffirm the importance of articulation between youth studies and youth policy-making. The result of unfruitful articulation produced, in this specific case, a 'misleading trajectory' (EGRIS, 2001; Walther, 2002; Biggart and Walther, 2006) taken by young adults whose individualized housing careers did not find, in the legal framework, the necessary conditions to be justified or maintained. This resulted in the decreasing process of individualized housing careers in a familistic context. Indeed, instead of allowing young adults to de-standardize their life courses, the new mechanism did exactly the opposite, by regulating access on the basis of age, house size, location and the number of rooms, by penalizing mobility and so forth.

7.9 This paper has shown that, although there is daily competition between the different life-course features, the analytical relationship between the institutionalization and individualization of the life course must be complementary, for a complete comprehension of the phenomena. That is true, irrespective of the type of welfare state, e.g. the so-called conservative or sub-protective types. Only with that bipolar attention can we grasp what is behind the European statistics and the labels attached on their behalf, which, ultimately, disguise or excuse the weakness or non-existence of public policies.

\section{Notes}

${ }^{1}$ If we associate these structures with individual lives, it becomes clear that the two main markers of the farewell to youth and consequent conquest of the status of adulthood are financial and residential independence. These transitions are not only the most important to the conception of what it is to be an 
adult, but also the ones that are least dependent on individual choice and that best illustrate the structural characteristics of the choice biography.

2'Designed to chart and explain the interaction between Europe's changing institutions and the attitudes, beliefs and behaviour patterns of its diverse populations' (European Social Survey web site, 2009).

${ }^{3}$ Years in which the individual: first entered paid employment or an apprenticeship; first left parents to live separately for two months or more; first lived with spouse or partner for 3 months or more; first married; plus the years the first child was born and the youngest child was born.

${ }^{4}$ The questions used for this purpose were: 'Have you ever been in paid employment or a paid apprenticeship of 20 hours or more per week for at least 3 months?', 'In what year did you first start working in a job like this?', 'In what year, if ever, did you first leave your parent(s) for 2 months or more to start living separately from them?', 'Have you ever lived with a spouse or partner for three months or more?', 'In what year did you first live with a spouse or partner for three months or more?', 'Are you or have you ever been married?', 'In what year did you first marry?', 'Have you ever given birth to/fathered a child?', 'How many children have you given birth to/fathered?', 'In what year was your (first) child born?', 'In what year was your youngest child born?' .

${ }^{5}$ Questions used for this indicator: 'To be considered an adult how important is it for a person to have left the parental home?', 'To be considered an adult how important is it for a person to have a full-time job?', 'To be considered an adult how important is it for a person to have lived with a spouse or partner?', and 'To be considered an adult how important is it for a person to have become a mother/father?'.

${ }^{6}$ Formal work: it was necessary to show a tax return to prove the 'stability' of the income.

7 This is an example of the chronologization process referred by Kohli: 'The temporalization of life has been largely keyed to chronological age as the basis criterion; this has resulted in a chronologically standardized 'normative life course" (Kohli, 2007: 255).

${ }^{8}$ See Nico, Magda (2005), Quem não casa também quer casa. A conquista de autonomia habitacional na construção das identidades d@s jovens e das (in)dependências familiares (Those who do not marry, want a house, too. The conquest of residential autonomy in the construction of youth identities and of (in)dependence on the family), MA thesis in 'Family and Society', ISCTE, Lisbon, Portugal.

${ }^{9}$ Official statistics on IAJ beneficiaries and applicants (unpublished).

${ }^{10}$ The data also shows us that the importance attributed to different markers of adulthood is gendered. Women's maturity seems to be taken more for granted, as all the markers of adulthood are less important for the recognition of female adult status than male adult status. The tendency to argue that an individual reaches adulthood whether or not he or she experiences these transitional events is, thus, more frequent for women than men. Having a full time job is the most striking example of that, since $56.7 \%$ of individuals consider that having a full time job is important or very important for a boy to be considered an adult, but only $42 \%$ have that opinion when it comes to women. This means the normal biography is expected much more from 'grown up women' than men. Residential autonomy presents a similar but less intense gender pattern. Thus, the most individualistic markers of adulthood are the ones that reveal most gender stereotypes, while the familial markers of adulthood become more egalitarian between the sexes (particularly parenthood). Therefore it is assumed that the emotional and developmental meanings/significance of conjugality and parenthood transcend the sex of the individual, while individualistic transitional events are socially interpreted from a gender perspective.

${ }^{11}$ It has been noted that in 'Northern Europe there is a pattern of leaving home early but with return home more likely; and that in the south, leaving is later, is more linked to marriage, and return home is less likely.' (lacovou, 2001: 1).

${ }^{12}$ The absence of Italy from this sample should be taken into account.

13 Though it could be the result of the 'sequencing fallacy'. On this subject, see Billari (2001: 124).

${ }^{14}$ Sweden is the only country to present the occurrence of marriage slightly after the birth of the first child (see Oinonen, 2004, who describes a similar tendency in Finland). This country presents a strong tendency towards non-marital conjugal cohabitation, thus there is a tendency to associate marriage not with the couple but the birth of a child. It is due to the birth of the first child that marriage gains importance for the couple.

${ }^{15}$ Sorted by age at the first experience of leaving the parental home (at least for three consecutive months).

${ }^{16}$ Used in the analyses of Aassve (2002) and lacovou (2001).

$1762 \%$ in Portugal. 


\footnotetext{
${ }^{18}$ Nonetheless, if we consider the sum of the 'regular job' as a primary source of income and 'training allowances or educational grants', Portugal presents a below-average percentage.

${ }^{19}$ The percentage of these young adults who look forward to conjugal co-residence at some time (approximately 63\%) is the same, in a representative sample of the country, as for those who would live with a spouse right away if they could (Vasconcelos, 1998: 217). Thus, the basic difference is that, in their life course, these young adults attribute two different timings to these two types of residential autonomy.

${ }^{20}$ Unpublished data from the National Housing Institute.

${ }^{21}$ For a detailed comparison, see Nico 2008, (Des)incentivo ao Arrendamento por Jovens.
}

\section{References}

AASSVE, A.; BILLARI, F.; MAZZUC, S. and ONGARO, F. (2002), 'Leaving home: a comparative analysis of ECHP data, Journal of European Social Policy , 12 (4), pp. 259-275.

ALLEN, J.; BARLOW, J.; LEAL, J.; MALOUTAS, T. and PADOVANI, L. (2004) Housing and Welfare in Southern Europe, Wiley-Blackwell.

ARNETT, J. (2000), 'High Hopes in a Grim World: Emerging Adults' Views of their Futures and 'Generation X', Youth Society, Vol. 31, pp. 267-286.

BAUMAN, Z.(2001), The individualized society, Cambridge: Polity Press, pp- 1-16.

BECK-GERNSHEIM, E. (2002), Reinventing the family: in search of new lifestyles, Cambridge: Polity Press.

BECK, U. (1992), Risk Society. Towards a New Modernity, London: Sage.

BIGGART, Andy; WALTHER, Andreas (2006), 'Coping with Yo-Yo-Transitions. Young adults' Struggle for Support, between Family and State in Comparative Perspective' in Leccardi, Cármen; Ruspini, Elisabetta (eds.), A new youth? Young people, generations and family lif e, Ashgate, Aldershot, pp. 41-62.

BILLARI, F. (2001) 'The analysis of early life courses: complex descriptions of the transition to adulthood', Journal of Population, Vol. 18 (2), pp. 119-142.

BILLARI, F. (2005), The Timing of Life: The organization of the life course in Europe , < <http://www.europeansocialsurvey.org/index.php?option=com_content\&task=view\&id=64\&ltemid=9> (accessed 15 January 2008).

BOIS-REYMOND, M. du (1998). 'I Don't Want to Commit Myself Yet. Young People's Life Concepts, Journal of Youth Studies. Vol. 1, No. 1, pp. 63-79.

EGRIS (European Group for Integrated Social Research) (2001), 'Misleading Trajectories: Transition Dilemmas of Young Adults in Europe', Journal of Youth Studies, Vol. 4 (1), pp.101 - 118.

ELCHARDUS, Mark; SMITS, Wendy (2006), 'The Persistence of the Standardized Life Cycle', Time and Society, Vol. 15, n²/3, pp. 303-326.

ELDER JR., G. (1975), 'Age Differentiation and the Life Course', Annual Review of Sociology , Vol.1, pp. $165-190$

ELDER JR., G. (1998), 'The Life Course as Developmental Theory', Child Development, Vol. 69 (1), pp 1-12. ESPING-ANDERSEN, Gosta (1990), The Three Worlds of Welfare Capitalism, Cambridge: Polity Press.

EUROBAROMETER (2003), Youth in New Europe, European Commission Directorate General Education and Culture, European Commission.

EUROPEAN SOCIAL SURVEY - 2006, in <http://www.europeansocialsurvey.org/> (accessed 15 January 2008).

EVANS, K.; HEINZ, W.R. (1994), Becoming adults in England and Germany, London, Anglo-German Foundation.

FLASH EUROBAROMETER (2007), Young Europeans. Survey among young people aged between 15-30 in the European Union - Summary, Directorate-General Communication, European Commission.

GALLAND, O. (1984) Les jeunes, Paris: Éditions La Découverte.

GALLAND, O. (1991) Sociologie de la jeunesse. L'entrée dans la vie, Paris: Armand Colin.

GALLIE, W. (1962), 'Essentially contested concepts' in Black, M. (Ed.), The Importance of language, pp. 
121-146, Englewood Cliffs, NJ: Prentice Hall.

GIDDENS, A. (2001), Modernidade e identidade pessoal, Oeiras: Celta.

GOODWIN, J.; O'CONNOR, H. (2005), 'Exploring Complex Transitions: Looking Back at the 'Golden Age' of From School to Work', Sociology, Vol. 39(2), pp. 201-220.

HOROWITZ, A. D.; BROMNICK, Rachel D. (2007), ' 'Contestable Adulthood': Variability and Disparity in Markers for Negotiating the Transition to Adulthood', Youth Society, Vol. 39, pp. 209-231.

IACOVOU, M. (2001), 'Leaving Home in the European Union', Working Papers of the Institute for Social and Economic Research, Paper 2001-18; Colchester: University of Essex.

INEICHEN, B. (1981), The housing decisions of young people, British Journal of Sociology, Vol.32, No. 2: 252-258.

KOHLI, M. (1985), 'Die Institutionalisierung des Lebenslaufs' (The Institutionalisation of the Life Course), Kolner Zeitschrift fur Sociologie und Sozialpsychologie (Cologne Journal for Sociology and Social Psychology), Vol. 37, pp. 1-29.

KOHLI, M. (2007) 'The Institutionalization of the Life Course: Looking back to look ahead', Research in Human Development, 4 (3-4), pp. $253-271$.

MAYER, K.; SCHOEPFLIN, U. (1989), 'The State and the Life Course', Annual Review of Sociology, Vol. 15, pp. 187-209.

MICHAEL, R.T.; FUNCHS, V. R., SCOTT, S.R. (1980), 'Changes in the Propensity to Live Alone - 19501976 ' in Demography, Vol. 17, No. 1, pp. 39-56.

MILLS, M.; BLOSSFELD, H-P. (2005) 'Globalization, Uncertainty and the Early Life Course. A Theoretical Framework' in Blossfeld, Hans-Peter; Klijzing, Erik; Mills, Melinda; Kurz, Karin (eds.), Globalization, Uncertainty and Youth in Society, New York: Routledge, pp 1-24.

MOLGAT, M. (2007), 'Do Transitions and Social Structures Matter? How 'Emerging Adults' Define Themselves as Adults', Journal of Youth Studies, Vol. 10 (5), pp. 495-516.

NAGEL, U.; WALLACE, C. (1997), 'Participation and Identification in Risk Societies: European Perspectives', in J. Bynner, L. Chisholm and A. Furlong (eds) Youth, Citizenship and Social Change in a European Context, Aldershot: Ashgate.

NICO, M. (2005), Quem não casa também quer casa. A conquista de autonomia habitacional na construção das identidades d@s jovens e das (in)dependências familiares, Dissertação de Mestrado em Familia e Sociedade, ISCTE. [The conquest of residential autonomy in the construction of youth identity and family (in)dependences. MA thesis]

NICO, M. (2008); Conjugality and Transition to Adulthood, ISA Research Committee on Family Research, RC06, 'Family Diversity and Gender', 9-13 September 2008, ISCSP, Lisbon, available on CD.

NICO, M. (2008), '(Des)Incentivos ao Arrendamento por Jovens' [(Dis)incentives for young people to rent] in Laureano, Raul M.S. and Soares, Helena Matos (Eds.), Perspectivas do Crédito à Habitação - 2008' [Perspectives on Mortgages], Número Especial da Colecção 'Temas em Métodos Quantitativos', Sílabo: Lisbon.

NORRIS, Michelle; SHIELS, Patrick (2004), 'Regular National Report on Housing Developments in European Countries, Synthesis Report', The Housing Unit, Dublin.

OINONEN, E. (2004), Finnish and Spanish Families in Converging Europe; Cityoffset Oy: Tampere.

PAIS, J. M. (1993), 'Culturas juvenis', Lisbon, Imprensa Nacional Casa da Moeda.

PAIS, J.M. (2001), Ganchos, tachos e biscates', Porto: Âmbar.

PAPPÁMIKAIL, L.; (2004), 'Relações intergeracionais, apoio familiar e transições juvenis para a vida adulta', Sociologia, Problemas e Práticas, n. ${ }^{\circ} 46$, pp. 91-116.

RINDFUSS, R. R. (1991), 'The young adult years: diversity, structural change and fertility' in Demography, 28(4), 493-512.

SCHWARTZ, S.; CÔTÉ, J.; ARNETT, J. (2005), 'Identity and Agency in Emerging Adulthood: Two Developmental Routes in the Individualization Process', Youth Society, Vol. 37; pp 201-229.

SETTERSTEN JR, R.; MAYER, K. (1997), 'The Measurement of Age, Age Structuring, and the Life Course', Annual Review of Sociology, Vol. 23, pp. 233-261.

VASCONCELOS, P. (1998), 'Práticas e Discursos da Conjugalidade e da Sexualidade dos Jovens 
Portugueses' in Jovens Portugueses de Hoje, Secretaria de Estado da Juventude, Celta, Oeiras, pp. 215306.

VINKEN, H. (2007), 'New life course dynamics? Career orientations, work values and future perceptions of Dutch youth', Young, Vol. 15 (1), pp. 9-30.

WALTHER, A. (2006), 'Regimes of youth transitions. Choice, flexibility and security in young people's experiences across different European contexts', Young, Vol. 14 (2): pp. 119-139.

WALTHER, A., \& HEJL, G.M.; JENSEN, T.B. (2002), 'Youth Transitions, Youth Policy and Participation state of the art report', RESEARCH PROJECT 'Youth Policy and Participation. Potentials of Participation and Informal Learning for the Transition of Young People to the Labour Market. A Comparison in Ten European Regions' available at <http://www.iris-egris.de/yoyo/pdf/YoyoWP1StateofArt.pdf>.

WESTBERG, A. (2004), 'Forever Young? Young People's Conception of Adulthood: The Swedish Case', Journal of Youth Studies, Vol. 7 (1), pp. 35-53.

WHITE, L. (1994), 'Co-residence and Leaving Home - Young Adults and their Parents', Annual Review of Sociology, Vol. 20, pp. 81-102.

ZITTOUN, T. (2007), 'Symbolic resources and responsibility in transitions', Young, Vol. 15; 193-211. 